\title{
Composição florística de Plantas daninhas na Cultura do FeiJão-Caupi no Sistema de Capoeira Triturada ${ }^{1}$
}

\author{
Floristic Composition of Weeds in the Cowpea (Vigna unguiculata) Culture under the Chopped \\ Secondary Forest System
}

\author{
MARQUES, L.J.P. ${ }^{2}$, SILVA, M.R.M. ${ }^{3}$, ARAÚJO, M.S. ${ }^{4}$, LOPES, G.S. ${ }^{5}$, CORREA, M.J.P. ${ }^{6}$, \\ FREITAS, A.C.R. ${ }^{7}$ e MUNIZ, F.H. ${ }^{8}$
}

\begin{abstract}
RESUMO - O plantio direto na capoeira é um sistema de substituição ao corte e queima que vem sendo implementado na Amazônia nas áreas de agricultura familiar. Como o manejo de plantas daninhas é essencial no processo produtivo, este trabalho visou realizar o levantamento florístico nas áreas de plantio direto na capoeira triturada e cultivada com feijão-caupi. A pesquisa foi conduzida em área de produtor rural no município de Zé Doca, Maranhão. O preparo da área foi realizado com um trator de rodas, juntamente com o implemento Ahwi FM600. A área foi cultivada inicialmente com milho, seguido do feijãocaupi BRS Guariba durante dois anos, sendo a avaliação das plantas daninhas realizada aos 30 e 60 dias após a semeadura, com um retângulo $(0,5 \times 0,3 \mathrm{~m})$ lançado 30 vezes. A cada lançamento era realizada avaliação, com as partes aéreas das plantas daninhas colhidas, para a contagem, identificação e secagem, visando à obtenção dos índices fitossociológicos (frequência, densidade, dominância relativa e indice de valor de importância). Foram identificados 51 táxons distribuídos em 22 famílias, 43 gêneros e 46 espécies. As famílias de plantas daninhas com maior número de espécies foram Cyperaceae (7), Fabaceae (7), Poaceae (6), Malvaceae (5) e Rubiaceae (4). No ano agrícola de 2006/2007, as espécies com maior IVI foram Cyperus diffusus, Fimbristylis dichotoma, Spermacoce verticillata e Cyperus sp. No ano agrícola de 2007/2008, as principais espécies foram Digitaria horizontalis, seguida de C. diffusus e Pavonia cancellata. As plantas de capoeira originárias de rebrotas apresentaram os maiores IVIs no ano agrícola de 2006/2007 e sofreram redução drástica em 2007/2008. Conclui-se que o cultivo progressivo reduz as plantas de capoeira e aumenta o extrato herbáceo.
\end{abstract}

Palavras-chave: Vigna unguiculata, plantio direto, vegetação de pousio, fitossociologia, plantas infestantes.

\begin{abstract}
The no-tillage system in secondary vegetation is a replacement to the slash-and-burn method, using annual crops such as cowpea in family farming in the Amazon. Since weed management is an essential part of the production process, this study aimed to survey the flora in no-tillage areas of a chopped secondary forest cultivated with cowpea. This work was conducted in a rural farming area in the municipality of Zé Doca, MA in the agricultural years 2006/2007 and 2007/2008. The preparation of the area was carried out with a wheel tractor using the implement ahwi FM600. The area was originally planted with maize followed by BRS Guariba cowpea for two years. Weed evaluation was carried out 30 and 60 days after sowing with a rectangle $(0.5 \times 0.3 \mathrm{~m})$, launched 30 times. Evaluation was performed every time, with the aerial parts of the weeds being harvested for counting, identification, and drying, to obtain the phytosociological indices (frequency, density, dominance index, and importance value). The families with the most weed species were Cyperaceae (7), Fabaceae (7), Poaceae (6), Malvaceae (5) and Rubiaceae (4). In the agricultural years
\end{abstract}

1 Recebido para publicação em 17.4.2010 e na forma revisada em 17.12.2010.

2 Eng-0-Agr ${ }^{\circ}$, Mestre em Agroecologia, Universidade Estadual do Maranhão-UEMA, São Luís-MA, <luiz1000x@yahoo.com.br>; ${ }^{3}$ Prof ${ }^{\underline{a}}$ Adjunto, Dr $\stackrel{a}{\text { a }}$, Dep. de Fitotecnia e Fitossanidade, UEMA, < rmalheir@yahoo.com.br $>$; ${ }^{4}$ Discente do Curso de Agronomia, UEMA, <mgrth_22@hotmail.com>; ${ }^{5}$ Eng $^{\mathrm{a}}$-Agr ${ }^{\mathrm{a}}$., Mestre em Agroecologia, UEMA, < gslopes01@hotmail.com>; ${ }^{6}$ Prof ${ }^{\mathrm{a}}$. Adjunto, Dr ${ }^{\text {. }}$, Dep. de Química e Biologia, UEMA, <mjcorreazea@hotmail.com>; 7 Pesquisador da Embrapa/Cocais e Planícies Inundáveis, $<$ cfreitas_br@yahoo.com.br>; ${ }^{8}$ Prof ${ }^{\mathrm{a}}$ Adjunto, Dr ${ }^{\mathrm{a}}$, Dep. de Química e Biologia, UEMA, <fhmuniz@yahoo.com>.

Planta Daninha, Viçosa-MG, v. 28, p. 953-961, 2010. Número Especial 
2006/2007, the species with the highest IVIwere: Cyperus diffusus, Fimbristylis dichotoma, Spermacoce verticillata and Cyperus sp. In the agricultural years 2007/2008, the main species were: Digitaria horizontalis, followed by $\boldsymbol{C}$. diffusus, Pavonia cancellata and $\boldsymbol{F}$. dichotoma. The secondary forest plants originated from sprouting presented the highest IVIs in the agricultural year 2006/2007 and suffered a drastic reduction in 2007/2008. Thus, it can be concluded that progressive cultivation reduces secondary forest plant sprouting and increases the herbaceous extract.

Keywords: Vigna unguiculata, no-tillage, fallow vegetation, phytosociology, weeds.

\section{INTRODUÇÃO}

Feijão-caupi, feijão-de-corda ou feijãomacassar (Vigna unguiculata) são uma excelente fonte de proteínas e contêm todos os aminoácidos essenciais, carboidratos, vitaminas e minerais; além disso, possuem muitas fibras dietéticas, baixa quantidade de gordura e não contêm colesterol. Apresentam ciclo curto, baixa exigência hídrica e rusticidade para se desenvolver em solos de baixa fertilidade. Por meio da simbiose com bactérias do gênero Rhizobium, têm a habilidade para fixar nitrogênio do ar (Embrapa, 2003). Essa cultura representa alternativa de renda e alimento para a população de baixa renda da região Nordeste do Brasil, que o consome sob a forma de grãos maduros ou verdes (Oliveira et al., 2003).

O sistema de preparo da área mais utilizado para o cultivo dessa cultura no Maranhão é o corte e a queima da vegetação, que consiste numa prática rotacional (pousio e cultivo) que utiliza o fogo para o preparo da área. O sistema de corte e queima é considerado insustentável devido à redução do tempo do pousio e aumento das perdas de nutrientes (Gehring, 2006). Na busca de práticas sustentáveis no preparo da área, estão sendo desenvolvidas técnicas pela Embrapa Amazônia Oriental, como o plantio direto na capoeira triturada, através do projeto Tipitamba. Este sistema consiste no uso de um implemento que corta a vegetação de pousio no nível do solo sem danificar o sistema de raízes das árvores e arbustos, triturando e espalhando simultaneamente o material vegetal sobre a área (Denich et al., 2005). Também é recomendado um período de pousio com o plantio de leguminosas de rápido crescimento, para acumulação de biomassa (Brienza Jr. et al., 2000).
No entanto, a cultura do feijão-caupi, como a de qualquer outra espécie agrícola, é afetada por fatores ecológicos que, direta ou indiretamente, podem prejudicar seu rendimento. As plantas daninhas constituem um dos fatores que mais influenciam o crescimento, o desenvolvimento e a produtividade da cultura do feijão-caupi, pois competem por luz, nutrientes e água, o que se reflete na redução quantitativa e qualitativa da produção (Freitas et al., 2009). Para a determinação de um manejo adequado das plantas daninhas, é imprescindivel a realização de um diagnóstico no sentido de identificar e quantificar a dinâmica dessas populações.

A fitossociologia das plantas daninhas compara as populações dessas plantas num determinado momento e espaço; as repetições programadas desses estudos podem indicar tendências de variação da importância de uma ou mais espécies ou populações, com essas variações podendo estar relacionadas às práticas agrícolas adotadas (Pitelli, 2000; Oliveira $\&$ Freitas, 2008). Os efeitos diferenciados dos sistemas de preparo do solo podem modificar a composição botânica da comunidade infestante (Jakelaitis et al., 2003). A constante atualização desses levantamentos fitossociológicos é imprescindível na região do trópico úmido em zona de baixa latitude geográfica, em razão de a dinâmica da flora infestante da lavoura apresentar rápidas mudanças (Albertino et al., 2004).

Como os estudos sobre composição florística de plantas daninhas em áreas de plantio direto na capoeira triturada são escassos no Estado do Maranhão, objetivou-se com este trabalho caracterizar a comunidade infestante nesse sistema tendo como cultivo o feijãocaupi em dois anos agrícolas. 


\section{MATERIAL E MÉTODOS}

A pesquisa foi conduzida nos anos agrícolas 2006/2007 e 2007/2008, em área de produtor rural no Povoado Igarapé Grande, Zé DocaMA, situado a $3^{\circ} 14^{\prime} 35^{\prime \prime}$ de latitude sul e 4549'26" de longitude oeste. O clima da região, segundo a classificação de Thorntwaite, é do tipo $\mathrm{B}_{2}$ rA'a”, clima úmido do tipo $\left(\mathrm{B}_{2}\right)$, com pequena ou nenhuma deficiência de água, megatérmico. Os totais pluviométricos variam entre 1.600 e $2.000 \mathrm{~mm}$, e a umidade relativa do ar anual, entre 79 e $82 \%$ (Geplan, 2002).

No preparo da área experimental, em novembro de 2006, houve a trituração da capoeira, utilizando-se o implemento Ahwi FM600 acoplado a um trator de pneus e, em seguida, espalhando os resíduos sobre o solo. O cultivar de feijão-caupi BRS Guariba inoculado com Rhizobium sp. foi semeado em maio/ 2007 e maio/2008, em sucessão à cultura do milho. A semeadura foi manual, com três sementes/cova, espaçamento de $0,50 \mathrm{~m}$ entre linhas e $0,25 \mathrm{~m}$ entre covas, numa área de $900 \mathrm{~m}^{2}$, perfazendo um estande de 7.200 plantas. Na adubação foram aplicados $50 \mathrm{~kg} \mathrm{P}_{2} \mathrm{O}_{5}$ ha $^{-1}$ e $100 \mathrm{~kg} \mathrm{~K}_{2} \mathrm{O} \mathrm{ha}{ }^{-1}$ em toda a área.

As avaliações das plantas daninhas foram feitas no período de desenvolvimento vegetativo da cultura, aos 30 e aos 60 dias após a semeadura (DAS), por meio de um retângulo de 0,50 x 0,30 m lançado ao acaso 30 vezes. A cada lançamento, as partes aéreas das plantas daninhas foram colhidas e contadas, identificando-se a família, o gênero e a espécie. As identificações das plantas daninhas foram realizadas através de análise do material, com consulta à literatura e envio de exsicatas ao laboratório de botânica-herbário da Embrapa Amazonia Oriental, em Belém-PA. A massa seca foi quantificada após a secagem em estufa com ventilação forçada de ar a $70{ }^{\circ} \mathrm{C}$ por 72 horas, até atingir massa constante.

Efetuou-se a determinação dos parâmetros fitossociológicos: densidade relativa (De.R), calculada pela fórmula proposta por Curtis \& Mc Intosh (1950), frequência absoluta (Freq) e relativa (Freq.R), dominância relativa (Do.R) e indice de valor de importância (IVI), que foram calculados por fórmulas propostas por Mueller-Dombois \& Ellemberg (1974).

$O$ índice de similaridade da composição florística foi calculado entre as avaliações (30 e 60 DAS) e entre os anos agrícolas (2006/2007 e 2007/2008), utilizando-se o índice de Jaccard e a construção de dendrograma com base no método de média do grupo (UPGMA), em que o agrupamento foi feito a partir da média aritmética dos seus elementos. Na análise de classificação foram utilizados os programas "Matriz", "Coef" e "Cluster" do programa FITOPAC (Shepherd, 1994).

Calculou-se o indice de diversidade de Shannon (H') (Magurran, 1988) para cada avaliação nos anos agrícolas, sendo ele chamado de indice Shannon-Weaver ou de indice do Shannon-Wiener $H^{\prime}$, usado para medir a diversidade com informação entrópica da distribuição, o tratamento das espécies, como simbolos, e o tamanho da respectiva população, como uma probabilidade.

$$
H^{\prime}=\sum_{i=1}^{S} p_{i} \ln p_{i}
$$

em que: ln é o logaritmo neperiano; $p_{i}=n_{i} / N ; n_{i}$ é o número de indivíduos amostrados da espécie $i$; e $N$ é o número total de indivíduos amostrados.

\section{RESULTADOS E DISCUSSÃO}

Foram identificados 51 táxons de plantas daninhas, sendo 46 em nivel de espécie e cinco de gênero, reunidos em 23 famílias botânicas nos anos agrícolas de 2006/2007 e $2007 / 2008$ (Tabela 1). A classe predominante foi dicotiledônea, $\operatorname{com} 74,51 \%$, corroborando os resultados de Freitas et al. (2009) e Salgado et al. (2007) em trabalhos de interferência de plantas daninhas na cultura do feijão-caupi e feijão-carioca, com dominância das dicotiledôneas na ordem de 63 e $62 \%$, respectivamente. A dominância das espécies de plantas daninhas da classe dicotiledônea está relacionada à própria classe de cultivo do feijão-caupi, ou seja, dicotiledônea. Conforme Pitelli (1987), as espécies selecionadas geralmente possuem características botânicas muito próximas às da espécie cultivada, podendo apresentar alto potencial competitivo com a cultura. 
Tabela 1 - Principais plantas daninhas encontradas no cultivo do feijão-caupi em área de capoeira triturada - período 2006/2007 e 2007/2008

\begin{tabular}{|c|c|c|}
\hline Família & Espécie & Nome comum \\
\hline Amaranthaceae & Alternanthera brasiliana (L.) Kuntze & Cabeça-branca \\
\hline Asteraceae & $\begin{array}{l}\text { Bidens pilosa } \mathrm{L} . \\
\text { Elephantopus mollis Kunth. } \\
\text { Emilia coccinea (Sims) G. Don } \\
\text { Erechtites hieraciifolius (L.) Raf. ex DC. } \\
\text { Melampodium divaricatum (Rich.) DC. }\end{array}$ & $\begin{array}{l}\text { Picão-preto } \\
\text { Língua-de-vaca } \\
\text { Pincel-de-estudante } \\
\text { Mato } \\
\text { Flor-de-ouro }\end{array}$ \\
\hline Cyperaceae & $\begin{array}{l}\text { Cyperus diffusus Vahl. } \\
\text { Cyperus flavus J. Presl \& C. Presl } \\
\text { Cyperus spp. } \\
\text { Fimbristylis dichotoma (L.) Vahl } \\
\text { Kyllinga odorata Vahl } \\
\text { Kyllinga brevifolia } \text { Rottb. } \\
\text { Scleria melaleuca } \text { Rchb. ex Schltdl. \& Cham. }\end{array}$ & $\begin{array}{l}\text { Capim } \\
\text { Capim } \\
\text { Capim } \\
\text { Capim } \\
\text { Capim } \\
\text { Capim } \\
\text { Tiririca-de-boi } \\
\end{array}$ \\
\hline Curcubitaceae & Indeterminado & Mato \\
\hline Euphorbiaceae & $\begin{array}{l}\text { Croton glandulosus L. } \\
\text { Croton lobatus L. }\end{array}$ & $\begin{array}{l}\text { Mato } \\
\text { Mato }\end{array}$ \\
\hline Fabaceae-caesalpinoideae & Senna obtusifolia (L.) H. S. Irwin \& Barneby & Mata-pasto \\
\hline Fabaceae-faboideae & $\begin{array}{l}\text { Aeschynomene americana } \mathrm{L} \text {. } \\
\text { Desmodium barbatum (L.) Benth. } \\
\text { Calopogonium muconoides Deves } \\
\text { Indigofera hirsuta } \mathrm{L} . \\
\text { Zornia reticulata } \mathrm{Sm} .\end{array}$ & $\begin{array}{l}\text { Angiquinho } \\
\text { Marvazinha } \\
\text { Calopogõnio } \\
\text { Anileira } \\
\text { Mato }\end{array}$ \\
\hline Fabaceae-mimosoideae & Mimosa invisa Mart. ex Colla & Sensitiva \\
\hline Hypericaceae & Vismia guianensis (Aubl.) Choisy & Lacre \\
\hline Juncaceae & Juncus sp. & Capim \\
\hline Lamiaceae & $\begin{array}{l}\text { Hyptis suaveolens (L.) Poit. } \\
\text { Marsypianthes chamaedrys (Vahl) Kuntze }\end{array}$ & $\begin{array}{l}\text { Bamburral } \\
\text { Hortlã-bravo }\end{array}$ \\
\hline Loganiaceae & Spigelia anthelmia $\mathrm{L}$. & Lombrigueira \\
\hline Malvaceae & $\begin{array}{l}\text { Melochia melissifolia } \text { Benth. } \\
\text { Corchorus argutus Kurth } \\
\text { Pavonia cancellata } \text { (L.) Cav. } \\
\text { Sida decumbens A. St.-Hil. \& Naudin } \\
\text { Sida glomerata Cav. } \\
\text { Triumfetta pentandra A. Rich } \\
\text { Urena lobata } \text { L. }\end{array}$ & $\begin{array}{l}\text { Mato } \\
\text { Mato } \\
\text { Erva } \\
\text { Reloginho } \\
\text { Reloginho } \\
\text { Erva } \\
\text { Erva }\end{array}$ \\
\hline Melastomataceae & Pterolepis trichotoma (Rottb.) Cogn. & Mato \\
\hline Phyllanthaceae & Phyllanthus niruri $\mathrm{L}$. & Quebra-pedra \\
\hline Plantaginaceae & Lindernia crustaceae (L.) I. V. Müell & Erva \\
\hline Poaceae & $\begin{array}{l}\text { Andropogon } \mathrm{sp} . \\
\text { Axonopus compressus (Sw) P. Beauv. } \\
\text { Cynodon dactylon (L.) Pers. } \\
\text { Digitaria horizontalis Willd. } \\
\text { Eragrostis ciliaris (L.) R. Br. } \\
\text { Imperata brasiliensis Trin. } \\
\end{array}$ & $\begin{array}{l}\text { Lajeado } \\
\text { Capim } \\
\text { Capim-de-burro } \\
\text { Capim } \\
\text { Capim } \\
\text { Capim-furão } \\
\end{array}$ \\
\hline Rubiaceae & $\begin{array}{l}\text { Oldenlandia corymbosa L. } \\
\text { Spermacoce latifolia Aubl. } \\
\text { Spermacoce verticillata L. } \\
\text { Spermacoce spp. }\end{array}$ & $\begin{array}{l}\text { Vassourinhas } \\
\text { Vassourinhas } \\
\text { Vassourinhas } \\
\text { Vassourinhas }\end{array}$ \\
\hline Schizaeaceae & Lygodium venustum $\mathrm{Sw}$. & Samambaia \\
\hline Turneraceae & Turnera ulmifolia $\mathrm{L}$. & Chanana \\
\hline Verbenaceae & Lantana camara L. & Chumbinho \\
\hline
\end{tabular}


As famílias com maior número de espécies foram Cyperaceae (7), Fabaceae (7), Poaceae (6), Malvaceae (5), Asteraceae (5) e Rubiaceae (4). Essas famílias são comuns na Amazônia, como foi observado em trabalho realizado por Araujo et al. (2007), que estudaram a supressão de plantas daninhas com feijão-de-porco e mucuna-preta na Amazônia maranhense, onde reportam as famílias Poaceae, Malvaceae e Cyperaceae como detentoras de maior número de indivíduos. Esses resultados confirmam pesquisa realizada por Leal et al. (2006) em banco de sementes de área cultivada em sistema de trituração, corte e queima no Pará, no qual as famílias dominantes foram Cyperaceae, Rubiaceae e Poaceae, indicando o potencial agressivo delas na região amazônica.

Quanto à diversidade $\left(\mathrm{H}^{\prime}\right)$ no sistema de trituração, o valor foi maior aos 30 DAS $(2,72$ e 2,14) e menor aos 60 DAS $(2,51$ e 1,95), respectivamente, nos anos agrícolas 2006/ 2007 e 2007/2008 (Tabela 2). Esses valores de diversidade estão próximos dos valores de ecossistemas naturais relativamente diversificados (indice de Shannon entre 3 e 4) (Gliessman, 2001). Isso pode estar relacionado ao processo de preparo do solo com triturador de capoeira, que tem como finalidade preservar as plantas de pousio. Esses resultados são
Tabela 2 - Índice de diversidade (H') no cultivo de feijão-caupi em área de capoeira triturada nos anos agrícolas 2006/2007 e 2007/2008, aos 30 e 60 DAS

\begin{tabular}{|c|c|c|}
\hline \multirow{2}{*}{ Ano agrícola } & \multicolumn{2}{|c|}{ Avaliação } \\
\cline { 2 - 3 } & 30 DAS & 60 DAS \\
\hline $2006 / 2007$ & 2,72 & 2,14 \\
\hline $2007 / 2008$ & 2,51 & 1,95 \\
\hline
\end{tabular}

condizentes com os encontrados por Rodrigues et al. (2007a,b), que apresentaram diversidade (H') média de 2,84 e 2,95 em sistema de capoeira triturada.

No ano agrícola 2006/2007, as espécies com maior IVI aos 30 DAS foram: $C$. diffusus $(34,27), F$. dichotoma $(23,79)$ e $S$. verticillata $(22,27)$, e aos 60 DAS: $F$. dichotoma $(38,00)$, Cyperus sp. $(30,20)$ e C. diffusus $(27,91)$ (Tabela 3). As plantas daninhas apresentaram maior IVI, superando as plantas originárias dos rebrotos de capoeira, cujo aumento da abundância do extrato herbáceo após a trituração da capoeira foi referenciado em trabalho de Rodrigues et al. (2007a). Segundo esse autor, o uso da máquina Ahwi FM600 para trituração de capoeira retarda o crescimento de espécies florestais provavelmente por causa do esmagamento, que compromete a rebrota, resultando em um processo danoso

Tabela 3 - Densidade relativa (De.R), frequência relativa (Freq.R), dominância relativa (Do.R) e índice de valor de importância (IVI) das principais plantas daninhas na cultura do feijão-caupi em área de plantio direto na capoeira triturada em Zé Doca-MA, aos 30 e 60 DAS, no ano agrícola 2006/2007

\begin{tabular}{|c|c|c|c|c|c|c|c|c|c|}
\hline \multicolumn{10}{|c|}{$2006 / 2007$} \\
\hline \multirow{2}{*}{ Espécie } & \multicolumn{4}{|c|}{30 DAS } & \multirow{2}{*}{ Espécie } & \multicolumn{4}{|c|}{60 DAS } \\
\hline & De.R & Freq.R & Do.R & IVI & & De.R & Freq.R & Do.R & IVI \\
\hline C. diffusus & 21,22 & 8,13 & 4,91 & 34,27 & F. dichotoma & 30,73 & 3,61 & 3,65 & 38,00 \\
\hline F. dichotoma & 17,35 & 4,88 & 1,56 & 23,79 & Cyperus sp. & 15,37 & 10,24 & 4,60 & 30,20 \\
\hline S. verticillata & 1,84 & 4,88 & 15,55 & 22,27 & C. diffusus & 11,71 & 4,22 & 11,99 & 27,91 \\
\hline C. muconoides & 1,02 & 4,07 & 15,12 & 20,20 & P. cancellata & 1,22 & 6,02 & 17,76 & 25,01 \\
\hline A. compressus & 13,06 & 4,07 & 2,63 & 19,76 & C. argutus & 1,71 & 6,02 & 8,05 & 15,78 \\
\hline Cyperus sp. & 9,80 & 3,25 & 1,48 & 14,53 & C. muconoides & 1,10 & 4,22 & 8,30 & 13,61 \\
\hline C. argutus & 1,63 & 5,69 & 6,78 & 14,11 & A. compressus & 8,90 & 2,41 & 1,17 & 12,49 \\
\hline P. cancellata & 1,63 & 4,07 & 7,43 & 13,13 & S. pterota & 5,12 & 5,42 & 1,91 & 12,45 \\
\hline E. mollis & 2,04 & 3,25 & 6,76 & 12,06 & S. latifolia & 1,34 & 4,22 & 6,64 & 12,20 \\
\hline V. guianensis & 2,45 & 4,88 & 3,59 & 10,92 & V. guianensis & 1,59 & 6,02 & 3,02 & 10,63 \\
\hline S. pterota & 3,27 & 1,63 & 1,02 & 5,91 & C. flavus & 5,61 & 1,81 & 2,72 & 10,14 \\
\hline S. latifolia & 1,63 & 4,07 & 2,29 & 7,99 & S. verticillata & 0,61 & 3,01 & 1,87 & 5,49 \\
\hline C. flavus & 0,00 & 0,00 & 0,00 & 0,00 & E. mollis & 0,12 & 0,60 & 2,51 & 3,23 \\
\hline \multicolumn{10}{|c|}{ Grupo de espécies } \\
\hline Plantas de Capoeira & 4,08 & 8,13 & 2,50 & 14,72 & Plantas de Capoeira & 2,68 & 9,64 & 4,91 & 17,23 \\
\hline
\end{tabular}


para a regeneração, tanto quanto o excesso de realização de capinas.

A disseminação das plantas daninhas também está relacionada às características da sucessão ecológica. Segundo Gehring et al. (2005), na avaliação da resiliência de floresta secundária após corte e queima, um moderado aumento no uso da terra tem pequeno efeito na acumulação de biomassa, mas forte efeito na estrutura da vegetação secundária, levando à redução de plantas lenhosas.

C. diffusus é a espécie de maior IVI (34.27) aos 30 DAS e a terceira mais importante (IVI=27,91) aos 60 DAS. O parâmetro que mais influenciou o IVI foi a De.R aos 30 DAS e De.R e Do.R aos 60 DAS (Tabela 2). Os altos IVIs dessa espécie estão relacionados à sua maior concentração na pré-Amazônia e Amazônia, sendo, conforme Kissmann (1997), considerada perene, favorecida pela temperatura elevada e umidade todo o ano. A dominância dessa espécie na região amazônica também foi condizente com o trabalho de Leal et al. (2006), que, estudando banco de sementes em áreas triturada e queimada no Pará, observaram que ela apresentou maior número de indivíduos antes e depois do preparo com trituração de capoeira e com tendência de maior número de indivíduos de espécies pioneiras em áreas trituradas em relação às com áreas queimadas.

$F$. dichotoma apresentou o segundo maior IVI $(23,79)$ aos 30 DAS e o maior IVI $(38,00)$ aos 60 DAS. O principal parâmetro que elevou o IVI foi a De.R nos dois momentos, o que está relacionado com o método de avaliação, que considera cada perfilho como um individuo na contagem. Além disso, essa espécie foi encontrada abundante em locais isolados, e essa abundância pode estar relacionada com a capacidade de a planta formar touceiras (Lorenzi 2008).

As plantas de capoeira apresentaram IVI igual a 14,72 e 17,23 aos 30 e 60 DAS, respectivamente. A Freq. R das plantas de capoeira foi parâmetro determinante para o IVI nas duas avaliações, indicando que esse grupo estava bem distribuído na área. Para Denich et al. (2005), o sistema de plantio direto na capoeira não visa destruir a vegetação de pousio, pois o implemento que tritura a capoeira corta a vegetação de pousio no nível do solo sem danificar sistemas de raízes de árvores e arbustos.

No ano agrícola 2007/2008, as principais espécies encontradas foram $D$. horizontalis $(82,78)$, C. diffusus $(36,87)$ e $P$. cancellata (29.80), aos 30 DAS, e C. diffusus $(78,42)$, $D$. horizontalis $(69,61)$ e $P$. cancellata $(27.63)$, aos 60 DAS (Tabela 4).

Nesse período foi observada mudança da composição florística com base no índice de similaridade de Jaccard, comparado ao ano de 2006/2007 (Figura 1). O indice de similaridade é corroborado pelos altos valores de IVI de outras espécies daninhas, como $D$. horizontalis, que não foi registrada no ano de 2006/2007. Conforme o dendrograma, existe similaridade entre os períodos de coleta dentro de cada ano e ocorre dissimilaridade entre os anos de 2006/ 2007 e 2007/2008.

A mudança na comunidade infestante pode estar relacionada à deterioração da camada de mulch no ano de 2007/2008, que proporciona espaços abertos, alterando as condições microclimáticas, pois novos fatores de pressão seletiva passam a atuar no agroecossistema. Outros fatores que podem estar relacionados com mudança da composição florística são os processos de disseminação das plantas daninhas, influenciados por fatores ambientais.

Em ambos os períodos (2006/2007 e 2007/ 2008), C. diffusus constituiu uma espécie relevante. Os fatores preponderantes nos valores de IVI foram a De.R e Do.R. O acúmulo de biomassa de $C$. diffusus, representado pela Do.R no segundo período de 2006/2007 e 2007/ 2008 , revela a sua importância no agroecossistema. A importância dessa espécie foi observada por Maciel et al. (2008), que, avaliando a composição florística em gramados de Paspalum notatum no município de Assis, São Paulo, verificaram que $C$. diffusus é uma das cinco espécies com maior IVI, sendo uma das maiores frequências e o maior valor de densidade nas áreas ensolaradas $\left(3,58\right.$ plantas $\left.\mathrm{m}^{-2}\right)$. C. diffusus é uma espécie do tipo $\mathrm{C} 4 \mathrm{e}$, dessa forma, pode apresentar grande vantagem competitiva quando infestando culturas agrícolas que também exijam os mesmos recursos (Kissmann, 1997). Plantas do tipo C4 apresentam alta afinidade com $\mathrm{CO}_{2}$, atuando 
Tabela 4 - Densidade relativa (De.R), frequência relativa (Freq.R), dominância relativa (Do.R) e índice de valor de importância (IVI) das principais plantas daninhas na cultura do feijão-caupi em área de plantio direto na capoeira triturada em Zé Doca-MA, aos 30 e 60 DAS, no ano agrícola de 2007/2008

\begin{tabular}{|c|c|c|c|c|c|c|c|c|c|}
\hline \multicolumn{10}{|c|}{$2007 / 2008$} \\
\hline \multirow{2}{*}{ Espécie } & \multicolumn{4}{|c|}{30 DAS } & \multirow{2}{*}{ Espécie } & \multicolumn{4}{|c|}{60 DAS } \\
\hline & De.R & Freq.R & Do.R & IVI & & De.R & Freq.R & Do.R & IVI \\
\hline D. horizontalis & 45,66 & 11,26 & 25,87 & 82,78 & C. diffusus & 24,90 & 18,80 & 34,73 & 78,42 \\
\hline C. diffusus & 13,06 & 10,60 & 13,21 & 36,87 & D. horizontalis & 40,32 & 12,78 & 16,51 & 69,61 \\
\hline P. cancellata & 2,28 & 13,25 & 14,27 & 29,80 & P. cancellata & 1,54 & 11,28 & 14,82 & 27,63 \\
\hline F. dichotoma & 9,19 & 4,64 & 2,34 & 16,17 & F. dichotoma & 9,35 & 5,26 & 4,06 & 18,67 \\
\hline C. muconoides & 0,70 & 5,30 & 7,08 & 13,07 & P. niruri & 2,07 & 9,02 & 3,10 & 14,19 \\
\hline E. mollis & 1,40 & 5,96 & 5,94 & 13,30 & E. mollis & 0,87 & 5,26 & 5,61 & 11,74 \\
\hline S. verticillata & 0,95 & 4,64 & 6,02 & 11,61 & C. muconoides & 0,53 & 5,26 & 5,35 & 11,15 \\
\hline S. latifolia & 0,89 & 5,96 & 4,43 & 11,27 & S. verticillata & 0,47 & 5,26 & 2,56 & 8,29 \\
\hline P. niruri & 1,08 & 4,64 & 0,99 & 6,71 & S. latifolia & 0,33 & 2,26 & 4,20 & 6,79 \\
\hline \multicolumn{10}{|c|}{ Grupo de espécies } \\
\hline Plantas de Capoeira & 0,19 & 1,32 & 0,44 & 1,95 & Plantas de Capoeira & 0,20 & 2,26 & 0,69 & 3,14 \\
\hline
\end{tabular}

especificamente com a carboxilase, atividade ótima em temperaturas mais elevadas e não saturação em alta intensidade luminosa (Silva et al., 2007).

D. horizontalis não foi registrada no ciclo de 2006/2007, porém apresenta altos valores de IVI no ciclo de $2007 / 2008$, com o maior IVI $(82,78)$ aos 30 DAS e o segundo maior $(69,61)$ aos 60 DAS. O parâmetro que elevou o IVI foi a De.R, tanto no primeiro quanto no segundo ano agrícola. Esses resultados são corroborados por Silva et al. (2005), que encontraram Digitaria sp. com maior importância relativa no plantio direto devido principalmente ao aumento da De.R das espécies desse gênero, superando os valores de Freq.R e Do.R; contudo, no preparo convencional, essas mesmas espécies apresentaram valores de Freq. $R$ elevados em relação às suas respectivas De.R e Do.R.

C. diffusus, $F$. dichotoma e D. horizontalis apresentaram alta De.R. na semeadura direta na capoeira triturada. O grau de interferência depende das manifestações de fatores ligados à comunidade infestante (composição específica, densidade e distribuição), além da própria cultura (espécie, variedade ou cultivar, espaçamento e densidade de plantio) e da época e extensão do período de convivência (Pitelli, 1987).

Em relação aos rebrotos de capoeira, foi observada redução ainda maior nos valores de IVIs e aumento das plantas daninhas pioneiras herbáceas. A redução drástica das plantas de capoeira é resultado do segundo ano consecutivo da atividade agrícola. O histórico do uso da terra tem significativo impacto na estrutura sucessional da vegetação de pousio, ou seja, em locais de uso intensivo ou pesado há redução no processo de desenvolvimento das árvores, predominando vegetação de sub-bosque na região amazônica (Moran et al., 2000).

No sistema de plantio direto da capoeira, o pousio é uma prática associada para a produção de biomassa e posterior trituração. Esse sistema é melhorado com o cultivo de leguminosas de rápido crescimento, que reduz o período de pousio e proporciona maior acúmulo de biomassa (Brienza Jr. et al., 2000; Denich et al., 2000). Os beneficios da capoeira estão relacionados à cobertura morta promovida pela trituração da vegetação secundária e das raízes das espécies da

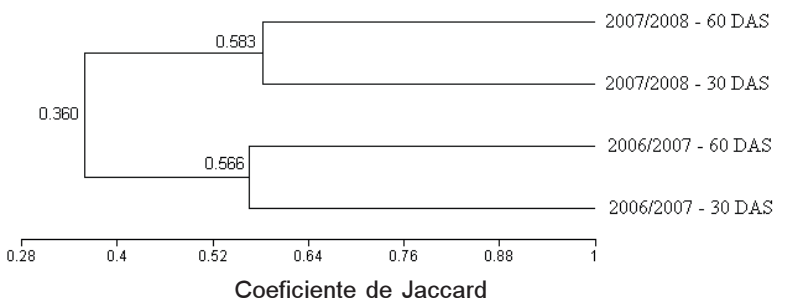

Figura 1 - Dendrograma de similaridade florística entre os períodos e anos de coleta - município de Zé Doca-MA pelo método de média de grupo (UPGMA), utilizando como coeficiente $o$ índice de Jaccard. 
capoeira, que atuam recapturando, para seu crescimento, os nutrientes que lixiviam no perfil do solo, conferindo sustentabilidade a esses agroecossistemas (Kato et al., 2004). Dessa forma, o preparo de áreas agrícolas com trituração de capoeira deverá ser utilizado respeitando-se os períodos de pousio, a fim de não degradar a vegetação, que apresenta vantagens ecológicas para a sustentabilidade do sistema.

Conclui-se que a utilização do sistema de plantio direto na capoeira triturada por dois anos consecutivos reduz a infestação das plantas de capoeira e aumenta a densidade de plantas daninhas herbáceas. As principais plantas daninhas na área de estudo foram C. diffusus, F. dichotoma, S. verticillata e Cyperus sp., aos 30 e 60 DAS no ano de 2007, e D. horizontalis, C. diffusus, $P$. cancellata aos 30 e 60 DAS no ano de 2008; C. diffusus e D. horizontalis foram as espécies com maior IVI nos anos 2007 e 2008,respectivamente.

\section{AGRADECIMENTOS}

À CAPES, pela concessão da bolsa, Embrapa Meio Norte, Embrapa Amazônia Oriental, Universidade Estadual do Maranhão, FAPEMA (Fundação de Amparo à Pesquisa e ao Desenvolvimento Tecnológico do Maranhão), ao Programa de Pós-Graduação em Agroecologia e ao proprietário da área, sr. Chico.

\section{LITERATURA CITADA}

ALBERTINO, S. M. F. et al. Composição florística das plantas daninhas na cultura de guaraná (Paullinia cupana), no Estado do amazonas. Planta Daninha, v. 22, n. 3, p. 351-358, 2004.

ARAUJO, J. C. et al. Supressão de plantas daninhas por leguminosas anuais em sistema agroecológico na préamazônia. Planta Daninha, v. 25, n. 2, p. 267-275, 2007.

BRIENZA JR., S. et al. Fallow Vegetation Enrichment with Leguminous Trees in the Eastern Amazon of Brazil: Trees Performance. In: GERMAN-BRAZILIAN WORKSHOP ON NEOTROPICAL ECOSYSTEMS, 2000, Hamburg Achievements and Prospects of Cooperative Research. Hamburg: 2000. p. 935-939.

CURTIS, J. T.; MC INTOSH, R. P. The interrelations of certain analytic and synthetic phytosociological characters. Ecology, v. 31, p. 434-435, 1950.
DENICH, M. et al. A concept for the development of fire-free fallow management in the Eastern Amazon, Brazil. Agric.

Ecosyst. Environ., v. 110, n. 1, p. 43-58, 2005.

DENICH, M.; KANASHIRO, M.; VLEK, P. L. G. The potential an dynamics of carbon sequestration in traditional an modified fallow systems of the eastern Amazon region, Brazil. In: LAL, R.; KIMBLE, J. M.; STEWART, B. A. (Eds.). Global climate change and tropical ecosystems Boca Raton: Lewis Publishers, 2000. 438 p.

\section{EMPRESA BRASILEIRA DE PESQUISA}

AGROPECUÁRIA - EMBRAPA. Embrapa Meio Norte

Cultivo do feijão caupi. Sistema de produção 2. Versão

eletrônica, 2003. Disponível em <http://

sistemasdeproducao.cnptia.embrapa.br/FontesHTML/

Feijao/FeijaoCaupi/importancia.htm $>$ Acesso em: 1 set. 2009.

FREITAS, F. C. L. et al. Interferência de plantas daninhas na cultura do feijão-caupi. Planta Daninha, v. 27, n. 2 , p. 241-247, 2009.

GEHRING, C.; DENICH, M.; VLEK, P. G. Resilience of secondary forester growth after slash-and-burn agriculture in central Amazonia. J. Tropic. Ecol., v. 21, p. 519-527, 2005.

GEHRING, C. Ambiente do trópico úmido e o manejo sustentável dos agrossistemas. In: MOURA, E. G.; AGUIAR A. C. F. (Orgs.). O desenvolvimento rural como forma de ampliação dos direitos no campo: princípios e tecnologias São Luis: Universidade Estadual do Maranhão, 2006. v. 2. p. 101-140

GERÊNCIA DE PLANEJAMENTO E DESENVOLVIMENTO ECONÔMICO - GEPLAN. Atlas do Maranhão. São Luís: Laboratório de Geoprocessamento, Universidade Estadual do Maranhão, 2002. 32 p.

GLIESSMAN, S. R. Agroecologia: processos ecológicos em agricultura sustentável. 2.ed. Porto Alegre: Universidade Federal do Rio Grande do Sul, 2001. 653 p.

JAKELAITIS, A. et al. Dinâmica populacional de plantas daninhas sob diferentes sistemas de manejo nas culturas de milho e feijão. Planta Daninha, v. 21, n. 1, p. 71-7. 2003.

KATO, O et al. Plantio direto na capoeira. Ci. Amb., v. 1, n. 1, p. 99-111, 2004.

KISSMANN, L. G. Plantas infestantes e nocivas. São Paulo: BASF, 1997. 824 p.

LEAL, E. C.; VIEIRA, I. C. G.; KATO, M. S. A. Banco de sementes em sistemas de produção de agricultura com queima e sem queima no município de Marapanim, Pará. B. Museu Paraense Emílio Goeldi, v. 1, n. 1, p. 19-29, 2006. 
LORENZI, H. Plantas daninhas do Brasil: terrestres, aquáticas, parasitas e tóxicas. 4.ed. Nova Odessa, Instituto Plantarum, 2008. 656 p.

MACIEL, C. D. G. et al. Composição florística da comunidade infestante em gramados de Paspalum notatum no município de Assis, SP. Planta Daninha, v. 26, n. 1, p. 57-64, 2008.

MAGURRAN, A. E. Ecological diversity and its measurement. Londres: Princeton University Press, 1988. $192 \mathrm{p}$.

MORAN, E. F. et al. Effects of soil fertility and land-use on forest succession in Amazônia. For. Ecol. Manag., v. 139, n. 1, p. 93-108, 2000.

MUELLER-DOMBOIS, D.; ELLEMBERG, H. Aims and methods of vegetation ecology. New York: John Willey \& Sons, 1974. 547 p.

OLIVEIRA, A. R.; FREITAS, S. P. Levantamento fitossociológico de plantas daninhas em áreas de produção de cana-de-açúcar. Planta Daninha, v. 26, n. 1, p. 33-46, 2008.

OLIVEIRA, A. P. et. al. Rendimento de feijão-caupi em função de doses e formas de aplicação de nitrogênio. Hortic. Bras., v. 21, n. 1, p. 77-80, 2003.

PITELLI, R. A. Estudos fitossociológicos em comunidades infestantes de agroecossistemas. J. Conseb, v. 1, n. 3, p. 1-7, 2000 .
PITELLI, R. A. Competição e controle das plantas daninhas em áreas agrícolas. Série Técnica IPEF, v. 4, n. 12, p. 24, 1987.

RODRIGUES, M. A. C. M.; MIRANDA, I. S.; KATO, M. S. A. Flora e estrutura da vegetação secundária após o uso de diferentes trituradores florestais. Pesq. Agropec. Bras., v. 42, n. 4, p. 459-465, 2007a.

RODRIGUES, M. A. C. M.; MIRANDA, I. S.; KATO, M. S. A. Estrutura de florestas secundárias após dois diferentes sistemas agrícolas no nordeste do Estado do Pará, Amazônia Oriental. Acta Amaz., v. 37 n. 4. p. 591-598, $2007 b$.

SALGADO, T. P. et al. Interferência das plantas daninhas no feijoeiro carioca. Planta Daninha, v. 25, n. 3, p. 443-448, 2007.

SILVA, A. A. et al. Biologia de plantas daninhas. In. SILVA, A.A.; SILVA, J. F. Tópicos em manejo de plantas daninhas. Viçosa, MG: Universidade Federal de Viçosa, 2007. 367 p.

SILVA, A. A. et al. Aspectos fitossociológicos da comunidade de plantas daninhas na cultura do feijão sob diferentes sistemas de preparo do solo. Planta Daninha, v. 23, n. 1, p. 17-24, 2005.

SHEPHERD, G. J. FITOPAC 1: manual do usuário. Campinas: UNICAMP/Departamento de Botânica, 1994. 